\title{
A tale of two glucose transporters: how GLUT2 re-emerged as a contender for glucose transport into the human beta cell
}

\author{
M. van de Bunt • A. L. Gloyn
}

Received: 14 May 2012 / Accepted: 22 May 2012 / Published online: 15 June 2012

(C) Springer-Verlag 2012

\begin{abstract}
Finding novel causes for monogenic forms of diabetes is important as, alongside the clinical implications of such a discovery, it can identify critical proteins and pathways required for normal beta cell function in humans. It is increasingly apparent that there are significant differences between rodent and human islets. One example that has generated interest is the relative importance of the glucose transporter GLUT2 in rodent and human beta cells. The central role of GLUT2 in rodent beta cells is well established, but a number of studies have suggested that other glucose transporters, namely GLUT1 and GLUT3, may play an important role in facilitating glucose transport into human beta cells. In this issue of Diabetologia Sansbury et al (DOI: 10.1007/s00125-012-2595-0) report homozygous loss of function mutations in $S L C 2 A 2$, which encodes GLUT2, as a rare cause of neonatal diabetes. Evidence for a beta cell defect in these subjects comes from very low birthweights, lack of endogenous insulin secretion and a requirement for insulin therapy. Neonatal diabetes is not a consistent feature of $S L C 2 A 2$ mutations. It is only found in a small percentage of cases $(\sim 4 \%)$ and the diabetes largely resolves before 18 months of age. This discovery is significant as it suggests that GLUT2 plays an important role in human beta cells, but the interplay and relative roles of other transporters differ from those in rodents. This finding should encourage efforts to delineate the precise role of GLUT2 in the human beta cell at different developmental time points and is a further reminder of critical differences between human and rodent islets.
\end{abstract}

\footnotetext{
M. van de Bunt • A. L. Gloyn ( $\triangle)$

Oxford Centre for Diabetes Endocrinology \& Metabolism,

University of Oxford, Churchill Hospital,

Oxford OX3 7LJ, UK

e-mail: Anna.gloyn@drl.ox.ac.uk
}

Keywords Beta cells · Glucose transporter · Human islets · Neonatal diabetes

Abbreviation
NDM Neonatal diabetes mellitus

Defining the genetic aetiology of diabetes is important as this information can affect treatment choice, informs on disease progression and has implications for family members [1]. The molecular characterisation of neonatal diabetes mellitus (NDM) has identified a number of genes that play critical roles in human pancreatic beta cell development and/ or function and has rapidly led to improved treatment options for some of these patients [2-4] (Fig. 1). Alongside its clinical value, human genetics is also a powerful tool for identifying or uncovering the key role of proteins in both normal physiology and pathophysiology. The discovery of the critical role of hepatocyte nuclear factor $1 \alpha$ (HNF1A) in beta cell development and function through its identification as a MODY gene exemplifies the potential of this approach [5].

Our current understanding of how the pancreatic beta cell works has largely been shaped by elegant studies in rodents that have inventoried the proteins present and investigated the cellular and phenotypic consequence of their loss or perturbation. Until recently, relatively little data have existed on human islets on account of difficulties in their acquisition. With the advent of islet transplantation programmes, access to human islets has become more widespread, facilitating their cellular and molecular characterisation. These efforts have identified crucial differences in the architecture, cell cycle control, ion channel composition and glucose transporter use between humans and rodents, resulting in questions over the direct extrapolation of rodent studies to 
Fig. 1 Key differences between human and rodent islets and critical proteins for human beta cell function as demonstrated by monogenic disorders. Human (a) and mouse (b) islets are co-labelled for insulin (red), glucagon (green) and somatostatin (blue), from which it can be observed that in mice the glucagon-containing cells are primarily located on the outside of the islet and insulincontaining cells on the inside, whereas in humans they are both present throughout the islet. In the schematic representation of the human beta cell (c) the proteins encoded by genes in which mutations result in monogenic syndromes of beta cell dysfunction (red) and those which differ in their composition between mouse and man (green) are displayed. BK channels, large conductance voltage- and $\mathrm{Ca}^{2+}$-activated $\mathrm{K}^{+}$channels; EIF2AK3, eukaryotic translation initiation factor $2 \alpha$ kinase 3 ; HNF1A, hepatocyte nuclear factor $1 \alpha$; HNF1B, hepatocyte nuclear factor $1 \beta$; HNF4A, hepatocyte nuclear factor $4 \alpha$; NeuroD1, neurogenic differentiation factor 1; NGN3, neurogenin 3; PDX1, pancreatic and duodenal homeobox 1; PLAGL1, Pleiomorphic adenoma-like protein 1; PTF1A, pancreas transcription factor $1 \alpha$; RFX6, regulatory factor X6
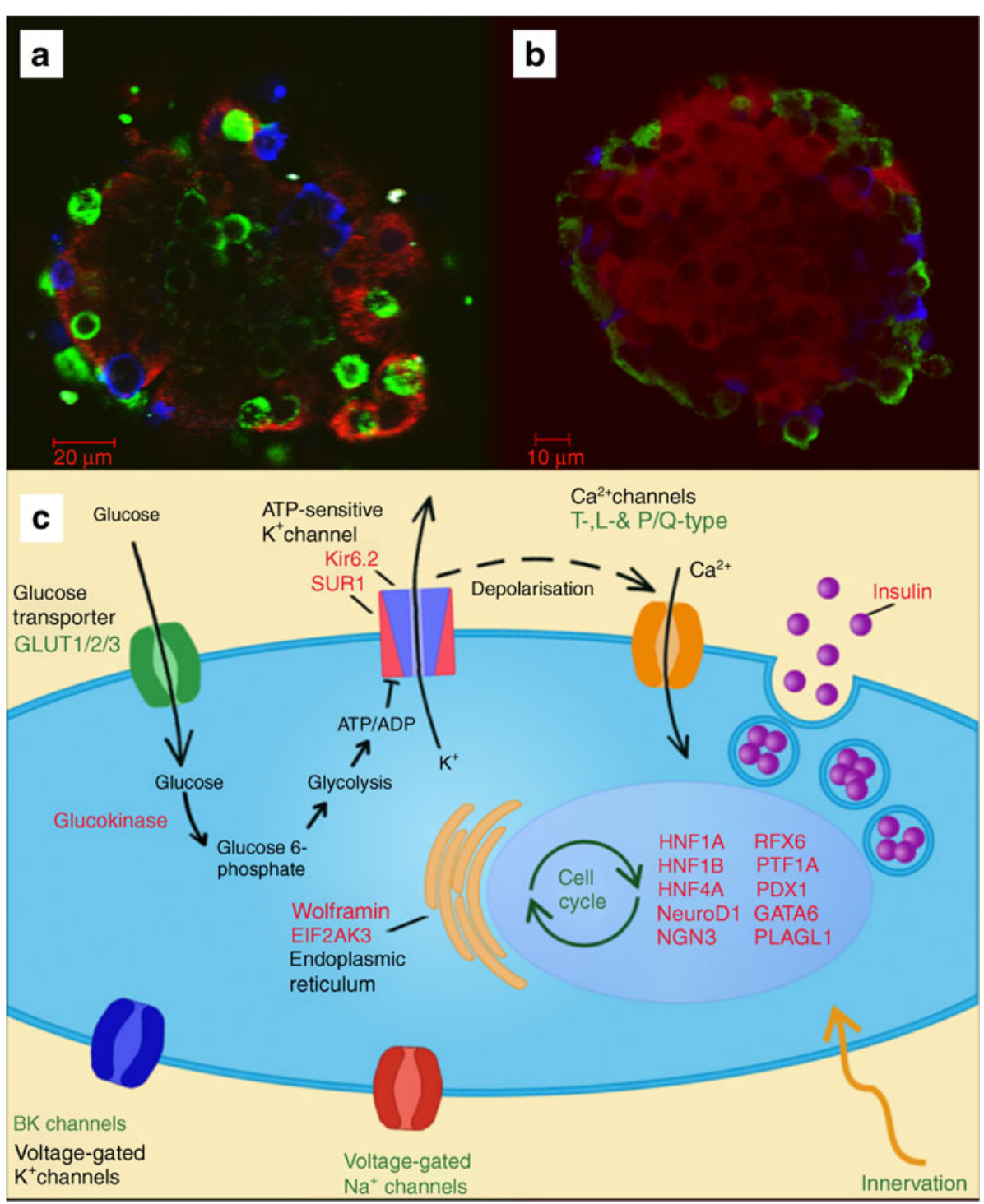

human physiology [6-9] (Fig. 1). The supremacy of GLUT2 in glucose transport in the rodent beta cell is not disputed, but a number of studies have suggested that in humans other glucose transporters, most notably GLUT1, may play an important role in facilitating glucose entry into the beta cell $[6,10-13]$. These studies have collectively shown that GLUT1 is more abundant at both the transcript and protein level and that the physiological properties of human beta cells are more consistent with the kinetic characteristics of GLUT1 [6, 12].

In the current issue of Diabetologia, Sansbury et al report the identification of recessive mutations in SLC2A2 (encoding the glucose transporter GLUT2) in patients with NDM [14]. Having sequenced $S L C 2 A 2$ in just over 100 cases of NDM in whom the known aetiologies had been excluded, five were found to have homozygous mutations. Of these, four had the transient variety of neonatal diabetes (TNDM), which resolves within a median of 18 months, and the fifth individual remains on insulin treatment at 28 months. The evidence for a beta cell defect in these individuals comes first from the observation that all five cases have very low birthweights, below the third centile, reflecting the critical role of fetal insulin as a growth factor in the third trimester. Second, two of the affected individuals presented with low C-peptide levels in the presence of clear hyperglycaemia. Third, all five patients responded to similar insulin doses to those used to treat other forms of neonatal diabetes, suggesting relative insulin deficiency was at least contributory, if not causal, to the diabetes.

This discovery adds valuable information to the discussion on the role of GLUT2 in human insulin secretion. While there are major defects in glucose-stimulated insulin secretion in Slc2a $2^{-1-}$ mice, leading to severe diabetes that is generally lethal within 2-3 weeks following birth, in man, recessive mutations in $S L C 2 A 2$ are a well-established cause of Fanconi-Bickel syndrome, which until this report did not feature diabetes as a recognised feature $[10,14,15]$. 
Fanconi-Bickel syndrome is typically characterised by a myriad of metabolic abnormalities, including hepatorenal glycogen accumulation, proximal renal tubular dysfunction and impaired glucose utilisation $[10,15]$. Furthermore, there is no evidence that common genetic variants in $S L C 2 A 2$ that are associated with fasting plasma glucose levels in humans do so via defects in beta cell function [16]. These phenotypic differences are supported by gene expression studies: Slc2a2 is by far the most abundantly expressed glucose transporter gene in rodent islets, whereas it is almost absent in humans $[6,12,13]$.

In human fetal islets, the presence of both GLUT1 and GLUT2 has been demonstrated throughout organogenesis, but their relative roles in glucose transport in the developing beta cell have not been determined $[13,17]$. During the third trimester, fetal insulin is an important growth factor, and the low birthweight reported in the individuals with GLUT2 deficiency supports reduced insulin secretion from fetal beta cells in utero. This observation is consistent with a role for GLUT2 in human beta cell function from at least week 27. In light of this finding it will now be important to study the birthweights of individuals with Fanconi-Bickel syndrome who do not present with NDM, as evidence of normal birthweight in these cases would argue against a reduction in insulin secretion in utero.

An imperative, but as yet unanswered question is why such a small percentage ( $\sim \%)$ of individuals with GLUT2 deficiency present with neonatal diabetes. To date, there is no evidence for a genotype-phenotype relationship and, in fact, family members with the same mutation have contrasting diabetic phenotypes [14]. Taken together this suggests that other forces, or glucose transporters, are at play in governing glucose entry into the beta cell, and that perhaps compensation can be offered by either GLUT1 or GLUT3, both of which are expressed at higher levels than GLUT2 in human beta cells [12].

Consistent with a compensatory role for other glucose transporters, three of the four individuals with NDM because of GLUT2 deficiency had diabetes that resolved, suggesting sufficient insulin can be released from the beta cell in the absence of GLUT2. It is possible that glucosestimulated insulin secretion in these patients will always be mildly impaired, but not sufficiently so to cause frank diabetes. Alternative explanations for the transient and infrequent nature of diabetes are that the beta cell defect is masked by the extra-pancreatic defects in glucose homeostasis in this syndrome, most notably, glycosuria. Further studies are evidently needed to unravel the relative roles and interplay between the three glucose transporters present in human beta cells.

The observation by Sansbury et al is a reminder that while rodents are valuable model organisms, the direct extrapolation of findings in rodent models to humans should be approached with caution. In instances where the human tissue is incompletely characterised, such as the human islet, this seems particularly pertinent. Through the study of human knockouts, GLUT2 has re-emerged as a contender for glucose transport in the human beta cell. The challenge now is to understand its precise role and relevance at different developmental time points in governing insulin secretion in humans.

Acknowledgements The authors thank E. Vergari, Q. Zhang and P. Rorsman (all at the Oxford Centre for Diabetes Endocrinology \& Metabolism) for supplying the confocal images of human and rodent islets.

Funding ALG is a Wellcome Trust Senior Fellow in Basic Biomedical Science (95101/Z/10/Z).

Duality of interest The authors declare that there is no duality of interest associated with this manuscript.

Contribution statement Both authors were responsible for the conception and design of the manuscript and wrote and approved the version to be published.

\section{References}

1. Thanabalasingham G, Owen KR (2011) Diagnosis and management of maturity onset diabetes of the young (MODY). BMJ 343: d6044

2. Waterfield T, Gloyn AL (2008) Monogenic $\beta$-cell dysfunction in children: clinical phenotypes, genetic etiology and mutational pathways. Ped Health 2:517-532

3. Pearson ER, Flechtner I, Njolstad PR et al (2006) Switching from insulin to oral sulfonylureas in patients with diabetes due to Kir6.2 mutations. N Engl J Med 355:467-477

4. Rafiq M, Flanagan SE, Patch AM, Shields BM, Ellard S, Hattersley AT (2008) Effective treatment with oral sulfonylureas in patients with diabetes due to sulfonylurea receptor 1 (SUR1) mutations. Diabetes Care 31:204-209

5. Yamagata K, Oda N, Kaisaki PJ et al (1996) Mutations in the hepatocyte nuclear factor- $1 \alpha$ gene in maturity-onset diabetes of the young (MODY3). Nature 384:455-458

6. De Vos A, Heimberg H, Quartier E et al (1995) Human and rat beta cells differ in glucose transporter but not in glucokinase gene expression. J Clin Invest 96:2489-2495

7. Bosco D, Armanet M, Morel P et al (2010) Unique arrangement of alpha- and beta-cells in human islets of Langerhans. Diabetes 59:1202-1210

8. Fiaschi-Taesch N, Bigatel TA, Sicari B et al (2009) Survey of the human pancreatic $\beta$-cell G1/S proteome reveals a potential therapeutic role for cdk-6 and cyclin $D_{1}$ in enhancing human $\beta$-cell replication and function in vivo. Diabetes 58:882-893

9. Braun M, Ramracheya R, Bengtsson M et al (2008) Voltage-gated ion channels in human pancreatic beta-cells: electrophysiological characterization and role in insulin secretion. Diabetes 57:1618-1628

10. Guillam MT, Hummler E, Schaerer E et al (1997) Early diabetes and abnormal postnatal pancreatic islet development in mice lacking Glut-2. Nat Genet 17:327-330

11. Chen C, Thorens B, Bonner-Weir S, Weir GC, Leahy JL (1992) Recovery of glucose-induced insulin secretion in a rat model of 
NIDDM is not accompanied by return of the B-cell GLUT2 glucose transporter. Diabetes 41:1320-1327

12. McCulloch LJ, van de Bunt M, Braun M, Frayn KN, Clark A, Gloyn AL (2011) GLUT2 (SLC2A2) is not the principal glucose transporter in human pancreatic beta cells: implications for understanding genetic association signals at this locus. Mol Genet Metab 104:648-653

13. Richardson CC, Hussain K, Jones PM et al (2007) Low levels of glucose transporters and $\mathrm{K}_{\mathrm{ATP}}{ }^{+}$channels in human pancreatic beta cells early in development. Diabetologia 50:1000-1005

14. Sansbury FH, Flanagan SE, Houghton JAL, et al SLC2A2 mutations can cause neonatal diabetes, suggesting GLUT2 may have a role in human insulin secretion. Diabetologia. doi:10.1007/ s00125-012-2595-0

15. Santer R, Steinmann B, Schaub J (2002) Fanconi-Bickel syndrome - a congenital defect of facilitative glucose transport. Curr Mol Med 2:213-227

16. Ingelsson E, Langenberg C, Hivert MF et al (2010) Detailed physiologic characterization reveals diverse mechanisms for novel genetic Loci regulating glucose and insulin metabolism in humans. Diabetes 59:1266-1275

17. Mally MI, Otonkoski T, Lopez AD, Hayek A (1994) Developmental gene expression in the human fetal pancreas. Pediatr Res $36: 537-544$ 